\title{
The association between improved quality diabetes indicators, health outcomes and costs: towards constructing a "business case" for quality of diabetes care - a time series study
}

\author{
Rachel Wilf-Miron ${ }^{1,2}$, Arkadi Bolotin ${ }^{3}$, Nesia Gordon ${ }^{4}$, Avi Porath ${ }^{5,6}$ and Ronit Peled ${ }^{7 *}$
}

\begin{abstract}
Background: In primary health care systems where member's turnover is relatively low, the question, whether investment in quality of care improvement can make a business case, or is cost effective, has not been fully answered. The objectives of this study were: (1) to investigate the relationship between improvement in selected measures of diabetes (type 2) care and patients' health outcomes; and (2) to estimate the association between improvement in performance and direct medical costs.

Methods: A time series study with three quality indicators - Hemoglobin A1c ( $\mathrm{HbA1c}$ ) testing, $\mathrm{HbA} 1 \mathrm{C}$ and $\mathrm{LDL}$ - cholesterol (LDL-C) control - which were analyzed in patients with diabetes, insured by a large health fund. Health outcomes measures used: hospitalization days, Emergency Department (ED) visits and mortality. Poisson, GEE and Cox regression models were employed. Covariates: age, gender and socio-economic rank.

Results: 96,553 adult (age $>18$ ) patients with diabetes were analyzed. The performance of the study indicators, significantly and steadily improved during the study period (2003-2009). Poor HbA1C (>9\%) and inappropriate LDL-C control (>100 mg/dl) were significantly associated with number of hospitalization days. ED visits did not achieve statistical significance. Improvement in $\mathrm{HbA} 1 \mathrm{C}$ control was associated with an annual average of $2 \%$ reduction in hospitalization days, leading to substantial reduction in tertiary costs. The Hazard ratio for mortality, associated with poor $\mathrm{HbA1C}$ and LDL-C, control was 1.78 and 1.17, respectively.

Conclusion: Our study demonstrates the effect of continuous improvement in quality care indicators, on health outcomes and resource utilization, among patients with diabetes. These findings support the business case for quality, especially in healthcare systems with relatively low enrollee turnover, where providers, in the long term, could "harvest" their investments in improving quality.
\end{abstract}

\section{Background}

During the last two decades, the quality of care has drawn increasing attention of health care systems. Among the cornerstones shaping this interest, were the inception of the Healthcare Effectiveness Data and Information Set (HEDIS) tool, which became available in 1993, with annual reporting of community-based performance measures of $90 \%$ of US health plans [1]; a series of articles on the quality of health care, published in the New England

\footnotetext{
* Correspondence: ronitpeled@yahoo.com

${ }^{7}$ Department of Health Systems Management, Faculty of Health Sciences,

Ben Gurion University of the Negev, Beer Sheva, Israel

Full list of author information is available at the end of the article
}

Journal of Medicine in 1996, illustrated how changes in measurement and quality improvement may affect physicians and patients over the coming decade [2]; and the 2001 Institute of Medicine (IOM) report, claiming that the US healthcare system needs to be re-designed in order to cross the "quality chasm" [3].

The term "Business Case" has been used to convince decision makers to invest in short-term actions which could lead to substantial benefits in the long term period of time. However, the lack of return on investments within a reasonable time period, has been an obstacle to making a business case for improving health care quality [4]. 
System-wide reengineering of care in the American Veterans Affairs (VA) healthcare system has resulted in significant improvements in diabetes care indicators $[5,6]$. In 2004, the British Government introduced a pay-for-performance and quality monitoring scheme with 136 indicators for family practices. The indicators covered management of chronic disease, practice organization, and patients' experiences with respect to care [7]. This scheme was associated with improvements in recorded quality of diabetes care in the first year; modest improvements in subsequent years; and with variation in care between population groups which diminished under the incentives, but remained substantial in some cases [8].

The Israeli National Quality Measurement Program (IOM) [9] has demonstrated substantial improvements in most diabetes care indicators during the past years, compared with those of the American HEDIS [10,11].

Numerous studies have shown the effect of organizational or local efforts on performance indicators; however, fewer studies have looked at the effect of improvement in performance indicators on improvement in either patients' health outcomes $[12,13]$ or medical costs. A recent publication by the IOM claims that the US healthcare system had become too complex and costly to maintain business as usual. The report suggests that transformational changes are required to shape a health care system which delivers the best care at the lowest cost [14].

Maccabi Healthcare Services (MHS) is the second largest Israeli health plan, providing community-based health services to two million members throughout the country. Service is delivered and managed by five regions through 150 branches. MHS, like other Israeli health plans, enjoys fully computerized health records. As a provider of community-based primary and secondary health care, MHS contracts with local hospitals to purchase tertiary care. The cost of hospitalization services is the single largest component in the MHS' budget (41.2\% of its expenses in 2009).

In 2004, MHS implemented a "Performance Measurement System" (PMS), which helped focus the organization's attention on selected clinical domains, including diabetes care. To encourage care improvement, annual targets were set for all units, with modest rewards given to units achieving their targets. Additionally, MHS has developed quality infrastructures at the central and regional levels to encourage adoption of quality concepts and tools and allow for organizational learning from success and failure.

Diabetes, which is a major chronic disease, is one of the clinical domains which has attracted intense MHS effort to improve the care provided to its members $[15,16]$. As evidence, 5 of the 24 indicators monitored by MHS' PMS are related to diabetes care.
The objectives of this study were: (1) to investigate the relationship between improvement in selected measures of diabetes (type 2) care and patients' health outcomes; and (2) to estimate the effect of improved performance on direct medical costs.

\section{Methods}

\section{Study design}

Time series study with repeated measurements.

\section{Setting}

The study was conducted by MHS, using retrospective data for the period 2003-2009.

\section{Focus of analysis}

Two intermediate outcome (HbA1C and LDL-Cholesterol control among patients with type 2 diabetes) and one process (HbA1C testing) measures were analyzed. Indicator selection was based on availability of complete longitudinal data and "stable" definitions (i.e., measure definition did not change during the period covered by the data). Health outcomes were represented by number of hospitalization days, Emergency Department (ED) visits and mortality.

\section{Study population}

All MHS members aged 18 and above listed in the MHS Diabetes Registry (DR), between 2003 and 2009 [17]. Mean time of follow up was $8.5( \pm 1.7)$ years.

\section{Data source}

HbA1C and LDL cholesterol (LDL-C) test results and documentation of $\mathrm{HbA} 1 \mathrm{C}$ testing were retrieved from the MHS PMS. Number of hospitalization days and ED visits (per patient, per year), time of death (date), age, gender and socio-economic rank (SER) were retrieved from the MHS central databank.

\section{Quality indicator definitions}

HbA1C testing: Documented at least once during the measurement year; poor Glycemic control: HbA1C > 9\% in the last recorded test for each year; LDL-C control: LDL-C $<100 \mathrm{mg} / \mathrm{dl}$ in the last recorded test for each year. All indicators were based on the American HEDIS definitions [1].

\section{Other definitions}

SER

The socio-economic rank of the member's residential neighborhood for the period studied, measured on a 10point scale, were retrieved from the census data kept by the Israel Central Bureau of Statistics [18]. 


\section{Statistical analysis}

Linear regression models were employed in order to evaluate the change in performance of selected indicators between the years 2003 and 2009.

\section{Repeated measurement data set structure}

The data set comprised for each DR registered patient all the information under investigation, for each year $(2003-2009=7$ lines 2009-2012 death information = additional 3 lines).

Poisson regression models were employed in order to account for the prevalence of zero counts in the data. The zero-inflated (or zero-altered) Poisson model allows over dispersion, through the splitting process, that models the outcomes as zero or nonzero.

Additionally, Generalized Estimating Equations (GEEs) were employed. GEEs fit generalized linear models of the dependent variable $y_{i t}$ (in our case: hospital days) with covariates $x_{i t}$

$$
g\left\{E\left(y_{i t}\right)\right\}=x_{i t} \beta, \quad y \sim F \text { with parameters } \theta_{i t}
$$

for $i=1, \ldots, m$ and $t=1, \ldots, n_{i}$, where there are $n_{i}$ observations for each group identifier $i$ (in our case, the patient's ID). $g($ ) is called the link function, and $F$ is the distributional family. Substituting various definitions for $g()$ and $F$ result in a wide array of models. In our case, $y_{i t}$ is assumed to be distributed negative binomial and $g($ ) is log, therefore:

$$
\log \left\{E\left(y_{i t}\right)\right\}=x_{i t} \beta, \quad y \sim \text { negative binomial with parameter } k=1
$$

yielding log-linear regression related models, depending on what is assumed for the within-group (within the particular patient's records, in our case) correlation structure.

Let $\boldsymbol{R}$ be the working correlation matrix for modeling the within-group correlation, a square $\max \left\{n_{i}\right\} \times \max \left\{n_{i}\right\}$ matrix. Let $\boldsymbol{R}_{t, s}$ denote the $t, s$ element. We assumed that the working correlation matrix is independent, therefore:

$$
\boldsymbol{R}_{t, s}= \begin{cases}1, & \mid t=s \\ 0, & \mid t \neq s\end{cases}
$$

Using GEEs with the independent correlation matrix corresponds to exploiting cluster option in General Linear Models (in our case, cluster is a set of the particular patient's records).

The global model takes the "time" as a reference point, while the dynamic model takes the variations in "time" along the study period. Global models were employed for hospitalization days and death. Dynamic models were employed for hospitalization days.

To evaluate association between the study year and HbA1C levels, the interaction variable "HbA1C_year" was computed by multiplying $\mathrm{HbA} 1 \mathrm{c}$ indicator (i.e., the binary, 0 -or-1, variable that equals 1 if $\mathrm{HbA} 1 \mathrm{c}$ is greater than the fixed at the particular year level of HbA1c) by the sequel year (starting with 0 as the year of entering into the study and going up with follow-up years).

To estimate the effect on death, a Cox Regression model was employed. This model fits the hazard, assuming an exponential function of the summation of the regression coefficients $b_{1}, \ldots, b_{k}$. The Cox model provides estimates of $b_{1}, \ldots, b_{k}$ but provides no direct estimate of the baseline hazard. For this task, data on death events were retrieved from MHS' central warehouse, and the years 2010-2012 were added.

To estimate average proportion of annual reduction in hospitalization days (saving days), the coefficient of dynamic model minus the coefficient of global model was calculated. To calculate cost savings, the number of hospitalization days saved was multiplied by cost per hospitalization day as noted on the Israeli Ministry of Health price list [19]. This price list is based on an average of direct cost between the internal and other general wards and corrected to the year of data analysis.

All models were adjusted for age, gender and SER considered as potential confounders. To analyze the data, STATA ver. 12 and SPSS ver.20 software were used. Alpha level for statistical significance was 0.05 .

\section{Results}

The analysis included data collected on 96,553 registered adult patients with diabetes. Mean age was $64.3( \pm 13.9)$, $43.5 \%$ were females and $64.7 \%$ belonged to the higher SERs (ranks 6-10) (Table 1).

During 2003-2009, rates of HbA1C testing increased from $43.8 \%$ to $69.6 \%$; rates of $\mathrm{HbA} 1 \mathrm{C}$ poor control decreased from $13 \%$ to $9.2 \%$, and rates of LDL-C control increased from $29.4 \%$ to $57.7 \%$ - all statistically significant (Table 2).

The Poisson model for hospitalization days (as the depended variable), revealed a significant association $(\mathrm{P}<0.0001)$ with poor HbA1C and LDL control (Table 3).

Both the global and dynamic GEE models revealed a positive and significant association between poor $\mathrm{HbA} 1 \mathrm{C}$ control (>9\%), lack of LDL-C control (>100 mg/dl) and number of hospitalization days (Table 4).

Table 1 Study population characteristics

\begin{tabular}{ll}
\hline Variable & $\mathbf{N}=\mathbf{9 6 , 5 5 3}$ \\
\hline Mean Age (years) & $64.3( \pm 13.9)$ \\
Females (\%) & 43.5 \\
SER* (\%) & \\
$1-5$ & 29.4 \\
$6-10$ & 64.7 \\
No available data & 5.9 \\
Mean time of follow up & $8.5( \pm 1.7)$ years
\end{tabular}

*SER: Socio-Economic Rank. 
Table 2 Performance rates (\%) of selected indicators, 2003-2009

\begin{tabular}{lllllllll}
\hline Indicator & $\mathbf{2 0 0 3}$ & $\mathbf{2 0 0 4}$ & $\mathbf{2 0 0 5}$ & $\mathbf{2 0 0 6}$ & $\mathbf{2 0 0 7}$ & $\mathbf{2 0 0 8}$ & $\mathbf{2 0 0 9}$ & $\mathbf{P}_{\text {value }}$ \\
\hline $\mathrm{HbA1C}>9 \%$ & $\mathrm{NM}^{+}$ & 13.0 & 11.1 & 11.7 & 11.1 & 9.3 & 9.2 & 0.010 \\
LDL Control $<100 \mathrm{mg} / \mathrm{dl}$ & 29.4 & 30.9 & 37.7 & 47.2 & 50.5 & 56.7 & 57.7 & $<0.001$ \\
HbA1C testing & 43.8 & 49.5 & 54.5 & 59.0 & 62.3 & 64.8 & 69.6 & $<0.001$ \\
\hline
\end{tabular}

*linear regression models; ${ }^{\dagger}$ Not measured.

The interaction with time (year) suggested that the proportion of patients with poor HbA1C and LDL control consistently and significantly decreased each year (Table 4). HbA1C testing did not reach statistical significance and was thus removed from further models $(\mathrm{P}=0.785)$.

The models for ED visits as a dependent variable were too weak $\left(\mathrm{LR} \mathrm{Chi}^{2}=73.4\right)$ to demonstrate any association with the independent variables.

Death as a dependent variable was positively and significantly associated with the following indicators: poor $\mathrm{HbA1C}$ control and inappropriate LDL-C control (>100 mg/dl). The hazard ratio for time of death (as a dependent variable) for $\mathrm{HbA} 1 \mathrm{C}>9 \%$ and LDL-C $>100 \mathrm{mg} / \mathrm{dl}$ indicators was 1.78 and $1.17(\mathrm{P}<0.001)$, respectively (Table 5$)$.

Calculation of the average annual drop in the proportion of patients with $\mathrm{HbA1C}>9 \%(0.52-0.50)$ revealed an average annual saving of $2 \%$ in hospitalization days, and a meaningful saving in hospitalization costs (Table 6).

\section{Discussion}

\section{Key findings}

Our study has demonstrated that over a 6-year-period, improvement in glycemic and cholesterol control was associated with significant decreases in hospitalization days, mortality and direct medical costs. ED visits failed to demonstrate a similar association.

\section{Results in context}

These results may be explained by the fact that improved glycemic and cholesterol control were important elements in the organization's efforts to improve quality of care, through multidisciplinary health promotion programs created within the framework of a performance monitoring system that implemented the organization's "call for action" [16].

Table 3 Results of Poisson regression models for hospitalization days (dependent variable), adjusted for age, gender and SER

\begin{tabular}{lllll}
\hline Variable & Coefficient & S.E. & 95\% Cl* & P value \\
\hline Hospitalization days & & & & \\
HbA1C $>9 \%$ & -0.059 & 0.015 & $-0.089--0.028$ & $<0.001$ \\
$L D L>100 \mathrm{mg} / \mathrm{dl}$ & 0.034 & 0.002 & $0.029-0.040$ & $<0.001$ \\
\hline
\end{tabular}

*95\% confidence interval; S.E = Standard Error.
In the early 1990s, the Institute of Medicine (IOM) $[20,21]$ defined quality as the "degree to which health services for individuals and populations increase the likelihood of desired health outcomes and are consistent with current professional knowledge". Quality of care can then be evaluated on the basis of structure, process, or outcome [22]. When used appropriately, both process and outcome measures can provide valid information about quality objectives [23].

The decision to choose hospitalizations, ED visits and mortality as health outcomes (the dependent variables) was based on data availability. Data on diabetes complications and long-term trends in diabetic patient satisfaction remain unavailable. It has been long claimed that the use of outcome measures is insufficient for quality of care assessment since most differences between patients receiving the same treatment result from factors associated with patients' characteristics - which are outside the control of health care providers [23]. Following our experience [24], it is believed that beyond the differences in personal characteristics, differences in care provided to MHS members tend to be marginal. However, differences in personal characteristics (gender, age and socioeconomic rank) were adjusted in all the statistical models. It is suggested that further research will be conducted with a control for patient characteristics such as self-efficacy,

Table 4 Results of three GEE models for hospitalization days and mortality (dependent variables) adjusted for age, gender and SER

\begin{tabular}{lccll}
\hline Variable & Coefficient & S.E. & 95\% Cl & P value \\
\hline Global ModelHospitalization days & & & \\
HbA1C $>9 \%$ & 5.35 & 0.63 & $4.1-6.6$ & $<0.001$ \\
HbA1C $>9 \% *$ Year & -0.50 & 0.07 & $-0.64--0.35$ & $<0.001$ \\
$\mathrm{LDL}>100 \mathrm{mg} / \mathrm{dl}$ & 0.13 & 0.05 & $0.02-0.24$ & 0.020 \\
Mortality & & & & \\
$\mathrm{HbA1C}>9 \%$ & 0.55 & 0.04 & $0.45-0.64$ & $<0.001$ \\
$\mathrm{LDL}>100 \mathrm{mg} / \mathrm{dl}$ & 0.20 & 0.03 & $0.14-0.27$ & $<0.001$ \\
$\begin{array}{l}\text { Dynamic ModelHospitalization days } \\
\text { HbA1C }>9 \%\end{array}$ & 5.75 & 0.67 & $4.2-6.8$ & $<0.001$ \\
$\mathrm{HbA1C}>9 \%$ *Year & -0.52 & 0.07 & $-0.67--0.36$ & $<0.001$ \\
$\mathrm{LDL}>100 \mathrm{mg} / \mathrm{dl}$ & 0.13 & 0.05 & $0.018-0.24$ & 0.022 \\
\hline
\end{tabular}

${ }^{*} 95 \%$ confidence interval. 
Table 5 Cox regression model for time to death (dependent variable), adjusted for age, gender and SER (2003-2012)

\begin{tabular}{lllll}
\hline Variable & Hazard ratio & S.E & $\mathbf{9 5 \% ~} \mathrm{Cl}^{\dagger}$ & P value \\
\hline $\mathrm{HbA} 1 \mathrm{C}>9 \%$ & 1.78 & 0.08 & $1.63-1.95$ & $<0.001$ \\
$\mathrm{LDL}>100 \mathrm{mg} / \mathrm{dl}$ & 1.17 & 0.039 & $1.09-1.25$ & $<0.001$ \\
\hline
\end{tabular}

Notes: ${ }^{\dagger} 95 \%$ Confidence Interval.

self-capability to manage the disease, compliance with medical regiment, and so forth.

Data obtained from the Israeli National Program for Quality Indicators (NPQI) in Community Healthcare [9] indicated a $0.25 \%$ annual increase in diabetes prevalence from 2004 to 2010. National census data indicated that diabetes-related mortality rates, adjusted for ethnicity and gender, have decreased by $24 \%$ from 2004 to 2010 [25], most probably due to better control of intermediate outcome measures and better care for diabetes complications. Although data on diabetes-related hospitalizations are not available, crude national figures indicate a steady increase in hospitalization days between 2000 and 2010 [26].

It is worth mentioning that the NPQI, instituted in 2004, contributed to each of the four Israeli health plans, including MHS, for development of quality improving infrastructures, which resulted in improved performance indicators in most measured domains. It is, therefore, suggested that the observed continuous improvement in the selected measures presented here is not exclusively the result of "natural improvement".

MHS' performance monitoring system was a necessary but insufficient element for the explanation of long-term care improvement. Regional "Quality Teams", comprised of physicians, nurses and other health professionals in managerial positions, were set up and trained to guide analysis of quality gaps and implementation of effective interventions. Resources were allocated to intervene in units which had exhibited wide gaps between actual

Table 6 Saving of hospitalization days due to improvement in $\mathrm{HbA1C}>9 \%$ indicator 2005-2012

\begin{tabular}{llll}
\hline Year & Hospital days & Saving & Saving in NIS* \\
\hline $2005^{*}$ & 94,447 & 1,927 & $3,944,000$ \\
2006 & 137,325 & 2,802 & $5,604,000$ \\
2007 & 176,131 & 3,594 & $7,188,000$ \\
2008 & 200,487 & 4,091 & $8,182,000$ \\
2009 & 195,606 & 3,991 & $7,982,000$ \\
2010 & 219,813 & 4,485 & $8,970,000$ \\
2011 & 205,563 & 4,195 & $8,390,000$ \\
2012 & 110,851 & 2,262 & $4,524,000$ \\
\hline
\end{tabular}

1NIS (Israeli Shekel) $=3.6$ US\$.

Note: *Since measurement and systemic quality improvement efforts were initiated in 2004, we calculated the decrease in hospitalizations as result in improved diabetes control from 2005. The effect of improved control in 2009 is expected to have an effect on hospitalization at least until 2012. performance and desired targets. Considerable effort has been invested in empowering patients throughout programs to increase treatment adherence [27], among other steps taken [16].

Our study also demonstrated association between significant reduction in mortality and improved glycemic and cholesterol control. Data from the United Kingdom has shown that the mortality risk among patients with Type 2 Diabetes is 1.6 times higher than that of the general population [28]. Landman and colleagues have reported that patients with diabetes evidencing poor glycemic control (HbA1C > 9\%) exhibited a hazard ratio of 2.21 for total mortality, compared with a hazard ratio of 1.0 among the control group with normal glycemic control levels ( $\mathrm{HbA} 1 \mathrm{C}<6.5 \%)$. This suggests that in order to increase life expectancy, interventions should focus mainly on patients evidencing poor control [29]. The literature also shows that correction of dyslipidemia (such as control of LDL-C) in patients with diabetes promotes reduction of macro-vascular disease, which contributes to cardio-vascular complications and shortened life span [30].

The models for ED visits (as a dependent variable) calculated in this study were too weak to produce significant statistical results. HbA1C performance (as an independent variable) was not found to be associated with either hospitalization days or death. It seems logical that this process variable is insufficiently powerful to explain these two outcomes. Additionally, $\mathrm{HbA} 1 \mathrm{C}$ is measured as performed at least once a year; the findings indicate that testing only once a year is insufficient for disease control and achievement of desired outcomes.

Providing appropriate care for patients with diabetes, especially those exhibiting complications resulting from poor disease control, demands considerable resources. Improving the quality of care to patients with diabetes and achieving better health outcomes is also costly [15,31-33]. Moreover, health care systems around the world are facing pressure to constrain costs, given the rise in medical sophisticated technologies and the aging of the population, among other reasons. Those trends prompt health care organizations' decision makers to expect a "business case" for quality improvement, meaning that these investments would have a "return on investment" (ROI) within a reasonable period of time. The annual average result of $2 \%$ reduction in hospitalization days through the reduction in poor glycemic control is a preliminary pivotal evidence for such a business case. The results comply with the results of several other studies [34-38], whose authors conclude that sustained reduction in $\mathrm{HbA} 1 \mathrm{C}$ levels among patients with diabetes is associated with significant cost savings within 1-2 years of level reduction. MHS, as all other Israeli HMOs, is characterized by a very low patient turn over, meaning 
that only a small portion of the population leaves its HMO during its life time. This fact urges the Israeli HMOs to invest in quality improvement, knowing that they can return their investments in the long term.

Blumenthal and colleague [4] argue that a leading obstacle to achieving quality in health care is the absence of a "business case" for quality. Healthcare system infrastructure is frequently accused of being inadequate to support such thinking. Furthermore, one of the root causes mentioned is the primitive quality measurement stage of science; if most healthcare providers are unable to estimate the total cost of investing in quality, how can one expect them to calculate the savings produced by their investment in interventions? Also, interventions to improve diabetes care produce return on investment only in the medium- to long-term (delayed savings). Therefore, healthcare organizations with a high turnover may not be able to achieve this return [39]. In times of austerity, the majority of budget cuts take place in the healthcare sector [40], which adds pressure on organizations to economically "justify" quality improvement investments.

\section{Study's strengths and limitations}

The strength of this study lies in the fact that data were analyzed for a very large study population $(\mathrm{N}=96,553)$ comprising all adult members of a major health plan, registered in the Diabetes Register, which increases the statistical validity of the findings. In addition, a robust statistical techniques were employed to support the hypothesized results.

Yet, the study has considerable limitations, which should be overcome in future studies: (1) The effect of only three diabetes performance measures was studied. Appropriate follow up with process measures such as eye and foot examinations or medical attention for nephropathy as well as intermediate blood pressure control were not included in the analysis because the measure's definition changed during the study period or the measure was not documented throughout the study period; (2) our information system, although fully computerized, was not designed to collect accurate and full data on the costs of quality improvement interventions or medical expenditures directly related to diabetes care; hence, the "investment" side of the "business case" argument was not thoroughly looked at. The data cannot be appropriately used to substantiate returns on investments in quality. Furthermore, the cost of hospitalization is subject to local agreements and contracts between HMOs and hospitals, and is not publicly transparent. The estimated cost saving is, therefore, based on the price list published by Israel's Ministry of Health, which may not fully reflect actual prices. 3 ). This study investigated the entire MHS' population; thus, a control group was not available, as all MHS members were under the quality improvement scheme. A further investigation with a case control design is recommended.

\section{Conclusion}

In conclusion, our study indicates the effect of continuous improvement in performance indicators on health outcomes and resource utilization among patients with diabetes. In health care systems with relatively low member turnover and beneficiaries who do not leave their HMO for a long period of time, this finding represents an important milestone, linking quality and cost, helping to construct the business case approach to quality; these conclusions may convince managers to invest scarce resources in care improvement.

\section{Ethics}

This study was a result of the routine analysis of data and did not required an ethical approval.

Competing interests

The authors declare that they have no competing interests.

\section{Authors' contributions}

All the authors of this manuscript had a substantial contributions to conception and design or analysis and interpretation of data and drafting of the article or critical revision for important intellectual content. $A B$; NG researched data. RWM $\mathrm{RP}$. wrote the manuscript and researched data. AP. reviewed/edited the manuscript and contributed to the discussion and reviewed/edited the manuscript. All authors read and approved the final manuscript.

\section{Author details}

${ }^{1}$ The Gertner Institute for Epidemiology and Health Policy Research, Ramat Gan, Israel. ${ }^{2}$ The School of Public Health, Sackler Faculty of Medicine, Tel Aviv University, Tel Aviv, Israel. ${ }^{3}$ Department of Public Health, Faculty of Health Sciences, Ben Gurion University of the Negev, Beer Sheva, Israel. ${ }^{4}$ Central Administration, Maccabi Healthcare Services, Tel Aviv, Israel. ${ }^{5}$ Maccabi Institute for Health Research, Tel Aviv, Israel. 'Epidemiology Department, Ben Gurion University of the Nege, Beer Sheva, Israel. ${ }^{7}$ Department of Health Systems Management, Faculty of Health Sciences, Ben Gurion University of the Negev, Beer Sheva, Israel.

Received: 16 June 2014 Accepted: 19 November 2014

Published: 1 December 2014

\section{References}

1. Schauffler $H H$, Rodriguez T: Exercising purchasing power for preventive care. Health Aff (Millwood) 1996, 15(1):73-85.

2. Blumenthal D: Quality of health care. PART 1: quality of care-what is It? N Engl J Med 1996, 335:891-894.

3. Institute of Medicine (IOM): Crossing the Quality Chasm: A New Health System for the 21st Century. Available at: http://www.iom.edu/CMS/8089/ 5432.aspx. Last access April 2014.

4. Blumenthal D, Ferris T: The Business Case for Quality: Ending Business as Usual in American Healthcare. Boston USA: Institute for Health Policy Massachusetts General Hospital; 2004.

5. Jha AK, Perlin JB, Kizer KW, Dudley RA: Effect of the transformation of the veterans affairs health care system on the quality of care. $N$ Engl J Med 2003, 348(22):2218-2227.

6. Kerr EA, Gerzoff RB, Krein SL, Selby JV, Piette JD, Curb JD, Herman WH, Marrero DG, Narayan KM, Safford MM, Thompson T, Mangione CM: Diabetes care quality in the veterans affairs health care system and commercial managed care: the TRIAD study. Arch Inter Med 2004, 141:272-281.

7. Roland M: Linking physicians' pay to quality of care - a major experiment in the United Kingdom. N Engl J Med 2004, 351:1448-1454. 
8. Kontopantelis E, Reeves D, Valderas JM, Campbell S, Doran T: Recorded quality of primary care for patients with diabetes in England before and after the introduction of a financial incentive scheme: a longitudinal observational study. BMJ Qual Saf 2013, 22(1):53-64.

9. National Program for Quality Indicators in Community Healthcare in Israel 2008-2010. Available at: http://healthindicators.ekmd.huji.ac.il/reports/lsrael\% 20quality\%20indicators\%202008-2010\%20English.pdf. Last access April 2014.

10. Rosen B, Pawlson LG, Nissenholtz R, Benbassat J, Porath A, Chassin MR, Landon BE: What the United States can learn from Israel about improving the quality of health care. Health Aff 2011, 30(4):1-9.

11. Jaffe DH, Shmueli A, Ben-Yehuda A, Paltiel O, Calderon R, Cohen AD, Matz E, Rosenblum JK, Wilf-Miron R, Manor O: Community healthcare in Israel: quality indicators 2007-2009. Isr J Health Policy Res 2012, 1(1):3.

12. Epstein AJ: Do cardiac surgery report cards reduce mortality? Assessing the evidence. Med Care Res Rev 2006, 63:403-426.

13. Profit J, Woodard LD: Perils and opportunities of comparative performance measurement. Arch Pediatr Adolesc Med 2012, 166(2):191-194.

14. National Research Council: Best Care at Lower Cost: The Path to Continuously Learning Health Care in America. Washington, DC: The National Academies Press; 2012.

15. Chodick G: The direct medical cost of cardiovascular diseases, hypertension, diabetes, cancer, pregnancy and female infertility in a large HMO in Israel. Health Policy 2010, 95:271-276.

16. Heymann AD: The implementation of managed care for diabetes using medical informatics in a large preferred provider organization. Diabetes Res Clin Pract 2006, 71:290-298.

17. Chodick G, Heymann AD, Shalev V, Kookia E: The epidemiology of diabetes in a large Israeli HMO. Eur J Epidemiol 2003, 18(12):1143-1146.

18. Israel Census Bureau. Available at: http://www1.cbs.gov.il/reader/?Mlval=cw_ usr_view_Folder\&ID=141. Last access April 2014.

19. Israeli Ministry of Health Hospitalization Price List. Available at: http://www. health.gov.il/publicationsfiles/sh-2011n.pdf Accessed August 2014.

20. Lohr KN, Donaldson MS, Harris-Wehling J: Medicare: a strategy for quality assurance. Quality of care in a changing health care environment. Qual Rev Bull 1992, 18:120-126.

21. Lohr KN (Ed): Medicare: A Strategy for Quality Assurance. Washington, D.C. National Academy Press; 1990.

22. Brook RH, Davies-Avery A, Greenfield S, Harris L, Lelah T, Solomon NE, Ware $J E \mathrm{Jr}$ : Assessing the quality of medical care using outcome measures: an overview of the method. Med Care 1977, 35(1):1-15.

23. Brook RH, McGlynn EA, Cleary PD: Quality of health care, part 2: measuring quality of care. N Engl J Med 1996, 335(13):966-970.

24. Wilf-Miron R, Tov OS, Lewinhoff I, Yaari E, Avitzour M, Viner A, Porath A, Kokia E: Equity promotion in maccabi healthcare services: from the equality report to an organizational action plan. Harefuah 2010, 149(4):210-213. 265, 264 (Hebrew).

25. Mortality and Life Expectancy: Annual Tables from the Statistical Abstract of Israel. Central Bureau of Statistics. Available at: http://www.cbs.gov.il/ shnaton63/st03_26x.pdf. Last Access April 2014.

26. Ministry of Health, Israel. Available at: http://www.old.health.gov.l/download/ docs/units/comp/ma2010/part1/clali_3.pdf. Last access April 2014. (Hebrew).

27. Mishali M, Omer H, Heymann AD: The importance of measuring selfefficacy in patients with diabetes. Fam Pract 2011, 28(1):82-87.

28. National Diabetes Audit Mortality Analysis 2007-2008: Key Findings on Mortality Rates for People With Diabetes in England, Report for the audit period 2007-2008. Available at: http://www.hqip.org.uk/assets/NCAPOPLibrary/Diabetes-Audit-Mortality-Audit-Report-2011-Final.pdf. Last Access April 2014.

29. Landman GW, Van Hateren KJ, Kleefstra N, Groenier KH, Gans RO, Bilo HJ: The relationship between glycaemic control and mortality in patients with type 2 diabetes in general practice (ZODIAC-11). Br J Gen Pract 2010, 60(572):172-175.

30. Krentz AJ: Lipoprotein abnormalities and their consequences for patients with type 2 diabetes. Diabetes Obes Metab 2003, 5(Suppl. 1):S19-S27.

31. National Institute of Diabetes and Digestive and Kidney Diseases: National Diabetes Statistics, 2007 Fact Sheet. Bethesda, MD: U.S. Department of Health and Human Services, National Institutes of Health; 2008

32. Maciejewski ML, Maynard C: Diabetes-related utilization and costs for inpatient and outpatient services in the veterans administration. Diabetes Care 2004, 27(Suppl 2):B69-B73.
33. Chodick G, Heymann AD, Wood F, Kokia E: The direct medical cost of diabetes in Israel. Eur J Health Econ 2005, 6:166-171.

34. Kuo S, Bryce CL, Zgibor JC, Wolf DL, Roberts MS, Smith KJ: Cost-effectiveness of implementing the chronic care model for diabetes care in a military population. J Diabetes Sci Technol 2011, 5(3):501-513.

35. Sadur CN, Moline N, Costa M, Michalik D, Mendlowitz D, Roller S, Watson R, Swain BE, Selby JV, Javorski WC: Diabetes management in a health maintenance organization: efficacy of care management using cluster visits. Diabetes Care 1999, 22:2011-2017.

36. Bodenheimer T, Wagner EH, Grumbach K: Improving primary care for patients with chronic illness: the chronic care model, part 2. JAMA 2002, 288(15):1909-1914

37. Wagner EH, Sandhu N, Newton KM, McCulloch DK, Ramsey SD, Grothaus LC Effect of improved glycemic control on health care costs and utilization. JAMA 2001, 285:182-189.

38. James BC, Savitz LA: How Intermountain trimmed health care costs through robust quality improvement efforts. Health Aff 2011, 30(6):1-7.

39. Leatherman S, Berwick D, lles D, Lewin LS, Davidoff F, Nolan T, Bisognano $M$ : The business case for quality: case studies and an analysis. Health Aff 2003, 22(2):17-30.

40. Reeves A, McKee M, Basu S, Stuckler D: The political economy of austerity and healthcare: cross-national analysis of expenditure changes in 27 European nations 1995-2011. Health Policy 2014, 115(1):1-8.

doi:10.1186/1472-6823-14-92

Cite this article as: Wilf-Miron et al.: The association between improved quality diabetes indicators, health outcomes and costs: towards constructing a "business case" for quality of diabetes care - a time series study. BMC Endocrine Disorders 2014 14:92.

\section{Submit your next manuscript to BioMed Central and take full advantage of:}

- Convenient online submission

- Thorough peer review

- No space constraints or color figure charges

- Immediate publication on acceptance

- Inclusion in PubMed, CAS, Scopus and Google Scholar

- Research which is freely available for redistribution 